\title{
Temas de debate y discusión
}

\section{The novisimos and the cultural transition}

1 ¿Cuáles son los aspectos estéticos y temáticos más importantes que pusieron en práctica los novísimos para la renovación de la poesía española?

2 Analiza la importancia del contenido, la forma y el estilo en dos autores novísimos.

3 ¿Podemos considerar que la poesía de autores como Leopoldo María Panero o Aníbal Núñez esconde un fuerte mensaje o crítica social?

\section{The power of poetry written by women}

1 ¿Es posible ofrecer una descripción precisa de lo que es la poesía escrita por mujeres? Analiza esta cuestión a partir de la obra de dos poetas mujeres de la antología.

2 Analiza la importancia del florecimiento de la poesía escrita por mujeres en la España de los años 80.

3 Analiza y compara el papel del cuerpo en la poesía escrita por mujeres en España a partir de dos o tres poemas de la antología.

\section{Poetry of experience and poetry of difference}

1 ¿Cuál es la importancia de la experiencia diaria y la vida personal del individuo en la poesía de la experiencia?

2 ¿Cuáles fueron las razones que permitieron a la poesía de la experiencia dominar el campo literario español de su momento?

3 ¿Cuál es la estética poética que defiende la poesía de la diferencia? Contesta la pregunta utilizando un poema de la antología como base y ejemplo. 


\section{The turn of a new millennium}

1 ¿Se puede apreciar una reacción estética, temática o incluso moral ante el nuevo milenio por parte de los poetas?

2 ¿Qué significado tiene la fragmentación del yo poético en la poesía de numerosos autores del nuevo milenio?

3 Analiza la importancia de los elementos visuales en la poesía del cambio de milenio.

\section{Young voices and new expressions}

1 ¿Cuáles son los aspectos más innovadores de la última poesía escrita en España?

2 ¿Qué tipo de temática y estética son las dominantes en la última poesía española?

3 Analiza la importancia de los varios campos semánticos predominantes en la poesía de Virginia Cantó y Vanesa Pérez-Sauquillo. Establece comparaciones entre las dos autoras y sus obras si es necesario. 